
MARCO MACIEL

MARCO MACIEL

é senador da República, tendo sido vice-presidente no governo Fernando Henrique Cardoso.

\section{O futuro das}

reformas

institucionais 


\section{REFORMA E AGENDA POLIITICA}

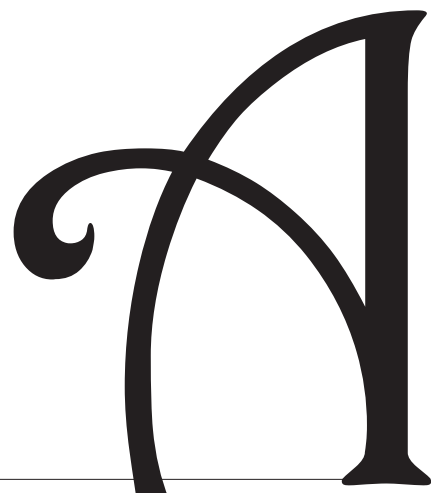

reforma eleitoral é tema que raramente deixou de figurar na agenda política do país. Não me refiro só à agenda atual, mas também às dos séculos XX e XIX. Adiferença reside na circunstância de que a expressão "reforma política", hoje tão cediça, no século XIX, com mais propriedade, designava-se "reforma eleitoral". Este é, por sinal, o título do livro publicado em 1875 pelo conselheiro Antônio Pereira Pinto, à época diretor da Secretaria da Câmara dos Deputados. Nele estão as propostas que, entre 1827 e 1874, tramitaram no velho Parlamento do Império, como objetivo de aprimorar a legislação eleitoral do país. Por ele se constata, por exemplo, que o projeto do deputado Ferreira França, em 1835, estabelecendo a eleição direta, só adotada pela Lei Saraiva em 1881, sequer foi considerado objeto de deliberação quando submetido ao turno regimental de apreciação preliminar de discussão. Os 46 anos que separam o projeto de Ferreira França da Lei Saraiva mostram a morosidade das mudanças políticas no Brasil a que Joaquim Nabuco se referiu, quando, na monumental biografia do seu pai (Um Estadista do Império), registrou que suas idéias como ministro da Justiça levavam em regra cerca de 30 anos para serem materializadas.

Hoje, é vezo generalizado referirmonos à reforma política tomando esse termo como sinônimo de reforma eleitoral e das questões adjetivas dela decorrentes. Nas propostas aprovadas pelo Senado Federal e em tramitação na Câmara dos Deputados - por sinal há tempos em condições de serem submetidas às deliberações do plenário - os temas relevantes cingem-se a três mudanças: 1) manutenção do sistema proporcional para eleição dos deputados; matéria constitucional (art. 45), adotandose a modalidade do voto em listas fechadas e bloqueadas; 2) fidelidade partidária e 3 ) adoção do financiamento público de cam- panhas. O financiamento público não é conseqüência do sistema de listas fechadas e bloqueadas. Ao contrário, o voto em lista é requisito para viabilizar o financiamento público impraticável com o modelo em vigor de listas abertas. Como repartir R $\$ 880$ milhões de recursos públicos nas eleições municipais entre 340 mil candidatos a vereador e mais de $15 \mathrm{mil}$ a prefeito, número do último pleito de 2004? A proposta do sistema de listas visa, exatamente, a tornar possível a distribuição do financiamento. Não entre os candidatos, o que seria inviável, mas entre os partidos, aos quais caberia a condução das campanhas eleitorais.

Sempre entendi que a reforma política é reiteradamente preconizada, mas lentamente materializada, depois de longos anos de discussão e debate, e exige um espectro bem mais amplo de medidas, com o objetivo de torná-las não só coerentes entre si, mas também consistentes com as demais soluções propostas. A meu juízo, a pauta das reformas deve abranger grande parte do universo dos diferentes componentes do nosso sistema político. Daí sempre ter dado preferência ao termo "reforma institucional", com o propósito de contemplar não só, como até agora, a opção entre os sistemas majoritário, proporcional ou misto. Entendo que questões referentes à organização federativa, ao relacionamento entre os poderes do Estado e à reforma legislativa devem integrar a agenda política com a mesma intensidade com que se defendem mudanças no sistema eleitoral. A reforma legislativa, por exemplo, é pressuposto da reforma do Legislativo e da modernização e simplificação da legislação brasileira. Trata-se de objetivo para se conseguir a consolidação legislativa prevista no art. 59 da Constituição de 1988 e já regulamentada pelas leis complementares de $\mathrm{n}$ os 95 , de 26 de fevereiro de 1998, e 107, de 26 de abril de 2001, mas até hoje sequer iniciada.

Embora entenda seja necessária a mudança do sistema eleitoral brasileiro para ensejar o fortalecimento dos partidos políticos, ele está razoavelmente atualizado e testado, compõe-se de um conjunto de disposições constantes dos arts. $2^{\circ}$ e $4^{\circ}$ da 
Constituição, que tratam, respectivamente, dos direitos e garantias constitucionais e da organização dos poderes, e das seguintes leis: a) a que estabelece a inelegibilidade e as incompatibilidades eleitorais (Lei Complementar no 64, de 18/5/1990); b) a que dispõe sobre a Justiça Eleitoral e a administração dos pleitos (Código Eleitoral, Lei no 4.737, de 25/7/1965); c) a que regula a organização e funcionamento dos partidos políticos (Lei no 9.096, de 19/9/1995) e d) a denominada lei das eleições (Lei no 9.504, de 30/9/1997), ambas, aliás, por mim sancionadas no exercício da Presidência da República, de cujas discussões participei com relatores e líderes no Congresso Nacional. Com exceção do Código Eleitoral, que é da década de 60 do século passado, mas sistematicamente atualizado, todo o restante do ordenamento legal foi aprovado na década de 90. De forma suplementar, mais de 20 mil resoluções do TSE regulam aspectos normativos da legislação vigente e esclarecem dúvidas suscitadas por candidatos, partidos e parlamentares. Esse sistema, portanto, não exige modificações maiores do modelo em vigor, salvo as imprescindíveis ao seu aperfeiçoamento.

\section{RELAÇÕES ENTRE OS PODERES}

A reforma política que interessa ao país transcende, como assinalei acima, esse universo de normas jurídicas, disposições legais e atos normativos que regulam os pleitos do segundo maior colégio eleitoral do mundo ocidental. Ela deve ser bem mais abrangente. Refiro-me, em especial, às instituições políticas, ao relacionamento entre os poderes do Estado, à organização federativa e, sobretudo, às práticas que constituem a nossa cultura política, velha de 500 anos, desde que aqui aportaram as estruturas do poder colonial, sob o qual vivemos por mais de três desses cinco séculos.

Quando me refiro às práticas, cito como exemplo efetivo o funcionamento do Poder Legislativo, no qual, de alguns anos até esta data, o formalismo dos atos se sobrepôs à relevância dos fatos. A reunião conjunta das duas casas do Congresso se cinge, além de eventuais e episódicas sessões de homenagens, às anuais de instalação das sessões legislativas e à destinada a receber o compromisso do presidente e do vice-presidente da República a cada quadriênio, por ocasião de suas respectivas posses. Na atual legislatura, à semelhança do que ocorreu na anterior, mais de 500 vetos encontramse pendentes de decisão do Congresso, fato que se repete há anos, a despeito do mandamento imperativo do art. 66, parágrafo 4: “O veto será apreciado em sessão conjunta, dentro de trinta dias a contar do seu recebimento, só podendo ser rejeitado pelo voto da maioria absoluta de Deputados e Senadores, por escrutínio secreto". Vivemos, em conseqüência, uma espécie de limbo legislativo em que há relevantes dispositivos legais que não vigoram e sua vigência está pendente de decisão conjunta das duas casas do Congresso. Trata-se de situação rigorosamente inédita na vida republicana do país, já que sob a Constituição do Império o instituto jurídico do veto era desconhecido, vez que, não concordando com a iniciativa do Parlamento, o imperador, titular dos poderes Executivo e Moderador, simplesmente deixava de sancioná-la e sua decisão era irrecorrível, não estando sujeita à apreciação do Parlamento.

O relacionamento entre o Poder Executivo e o Legislativo é outra das questões institucionais pendentes da nossa organização institucional. Enquanto o primeiro debita ao Congresso, sistematicamente, lentidão no complexo sistema de tomadas de decisões, que é a apreciação das leis de diferentes níveis hierárquicos, este reclama do Executivo o uso imoderado e abusivo do instituto das medidas provisórias, as chamadas MPs, instrumento desconhecido em nossa história profissional, até a promulgação do texto em vigor, trasladado literalmente da constituição parlamentarista da Itália de 1946. É, em última análise, um mecanismo que provoca desequilíbrio no sistema de freios e contrapesos, essencial ao princípio da divisão dos poderes, existente há mais de dois séculos e que as emendas 
constitucionais nos 8/1995 e 32/2002 não foram capazes de solver.

$\mathrm{O}$ que ocorre nas relações ExecutivoLegislativo verifica-se com igual ou maior intensidade entre o Executivo e o Judiciário, de um lado, e entre o Judiciário e o Legislativo, do outro. No primeiro caso, em razão da insistência do Executivo na prática de atos já decididos pacífica e tranquiilamente em seu desfavor por todas as instâncias da Justiça, o que tumultua a rotina dos tribunais superiores, obrigandoos a apreciar ações já decididas em primeira instância. E, na visão do Executivo, pela sucessão de recursos judiciais, cautelares uns, protelatórios outros, que perturbam a administração, quando não a imobilizam. Entre o Legislativo e o Judiciário, há também um contencioso de razoável dimensão. No caso da Justiça Eleitoral, pordecidir ultimamente sobre matérias que são substantivamente de natureza legal, como a questão das coligações para fins eleitorais. E da parte do Judiciário, pela lentidão com que o Legislativo atua na atualização da legislação processual, cujos ônus terminam debitados aos tribunais, por falta de operosidade do Congresso em matéria de sua competência.

São questões, portanto, mal resolvidas na Constituição, em face do desmedido crescimento do poder e das estruturas do Estadoe doespírito corporativo que preponderou nas constituintes que, historicamente, jamais se preocuparam em definir, preliminarmente, o que é de natureza constitucional e o que deve ser deixado à competência da legislação ordinária.

\section{ORGANIZACÃO FEDERATIVA}

O federalismo é outra das relevantes questões abertas da agenda político-institucional. O Brasil independente viveu 67 anos, a partir de 1822, como Estado unitário que o Ato Adicional de 1834, ao extinguir os Conselhos Gerais de Províncias e criar as Assembléias Legislativas Provinciais, instituiu, o que o historiador Pedro Calmon designou de "semifederalismo". Nos 118 anos seguintes, experimentamos todas as modalidades de organização federativa. Desde o modelo de viés norte-americano adotado em 1891, a primeira Constituição Republicana, passando pela volta do unitarismo do Império, restaurado durante o Estado Novo, até chegarmos ao chamado federalismo "compartilhado", ou "solidário", que começou a ser aplicado com a Carta de setembro de 1946. Só aí teve, a meu ver, início a discriminação de rendas em nosso sistema tributário, partilhando as receitas públicas entre a União, os estados e os municípios. A nova sistemática induziu à proliferação dos municípios como forma de aumentar, por essa via, através da repartição do imposto de renda, os recursos a eles destinados, o que implicava benefício indireto para os estados em que se localizavam.

Essa discriminação de renda se manteve desde então como meio de amenizar a assimetria econômica, social, demográfica e territorial de nosso federalismo republicano. Para evitar as crescentes demandas por recursos tributários dos demais entes federativos, a União passou, a partir de 1988, a aumentar a carga tributária com a adoção de contribuições, gênero da espécie tributos que se tornou renda exclusiva do governo federal. As reivindicações por sua partilha tendem a progredir de forma geométrica, evidência da necessidade de urgente reformulação no sistema tributário nacional, consentânea não somente a demandas de estados e municípios, mas adequada, sobretudo, às necessidades dos cidadãos.

Fundos destinados aos financiamentos das áreas de infra-estrutura, como transportes, portos, aeroportos e comunicações, cujos recursos têm sido esterilizados sob o argumento de gerar superávit primário, indispensável à higidez das contas públicas, precisam ser blindados contra o contingenciamento orçamentário, sob pena de estarmos substituindoo planejamento plurianual de caráter permanente, insistentemente reclamado pelo país e exigido pela Constituição, por programas ocasionais sujeitos às incertezas das sucessões presidenciais. 
A repartição harmônica entre competências constitucionais e recursos para a sua materialização deve obedecer ao sadio princípio federativo, segundo o qual nada do que possa ou deva ser feito pelos municípios seja atribuído aos estados, e nada do que possa e deva ser feito com maior racionalidade e eficiência pelos estados seja arrogado pela União, conforme recomenda o princípio da subsidiariedade.

Em outras palavras, antes de repensarmos o sistema representativo com seus componentes essenciais e interdependentes - o sistema eleitoral, o sistema partidário e o sistema de governo -, é indispensável rediscutirmos o próprio sistema político que inclui os modelos de organização do Estado, a começar por nossa estrutura federativa. $\mathrm{Ou}$ seja, escolhermos a forma de Estado, a forma e sistema de governo que mais nos convém. Definidas as atribuições e redistribuídos os recursos retirados da sociedade, para manutenção do Estado e dos governos, outra tarefa prioritária é a de evitarmos os paralelismos onerosos das funções do poder público estimulados pela crescente burocracia oficial em todos os poderes do Estado e em todos os níveis de governo.

Nosso sistema tributário talvez seja dos mais onerosos por se multiplicar pelas três instâncias de governo, gerando sobreposição das diferentes atribuições que as compõem: a função de tributação, a função de fiscalização e a função de arrecadação. União, estados e municípios mantêm enormes estruturas para fiscalizar os tributos a que estão obrigados os contribuintes, e não para fiscalizar as pessoas físicas e jurídicas que a eles estão sujeitos. O resultado é que exigências fiscais, como a inscrição no cadastro fiscal, multiplicam-se por três, num paralelismo rigorosamente dispensável que onera cada vez mais o "custo Brasil". Tributos não declaratórios e refratários à sonegação, como o que tem por base a movimentação financeira, podem ser uma alternativa para a simplificação do sistema tributário, desde que as verbas geradas sejam suficientes e bastantes para atender às necessidades de geração de meios nas diferentes esferas de nosso sistema federativo.

\section{OS SISTEMAS ELEITORAL E PARTIDÁRIO}

Os sistemas eleitoral, partidário e de governo são esferas de ação independentes. A experiência empírica demonstra, não só em nosso caso, mas de outros países que adotam o sistema proporcional, as conseqüências que o professor Maurice Duverger procurou demonstrar no seu livro pioneiro Os Partidos Políticos. Esse sistema favorece a proliferação do espectro partidário, enquanto o sistema majoritário privilegia a sua contenção.

O pluralismo, sob o ponto de vista ideológico e doutrinário, é requisito essencial à democracia. Mas, sob ambos os pontos de vista, não há nem nunca houve em toda a história do pensamento político mais do que duas, três ou quatro concepções diferentes. Sistemas com uma ou duas dezenas de partidos com representação parlamentar, como tem sido usual nos últimos 50 anos, entre nós, costumam, muitas vezes, refletir apenas interesses de caráter personalista e não os de natureza doutrinária, programática ou filosófica. Os sistemas proporcionais tornaram-se a regra geral a partir do século XX e os majoritários, exceção a essa tendência quase universal. Eles constituem a forma de assegurar o pluralismo político e atender às distintas peculiaridades nacionais, e às implicações políticas, de questões sociais, étnicas, religiosas, demográficas ou econômicas.

Por isso mesmo, é fora de dúvida que os sistemas proporcionais necessitam de medidas adicionais que favoreçam a contenção partidária, ou pelo menos evitem sua excessiva proliferação. Entre elas, a mais bem-sucedida é a cláusula de desempenho ou de barreira utilizada em mais de 40 democracias contemporâneas e que teve início na antiga República Federal Alemã em 1949. Esse instrumento vem sendo tentado entre nós, em diferentes modalidades, desde 1946 , quando a legislação eleitoral estabeleceu o número mínimo de 10 mil votos para que os partidos existentes tivessem direito à 
representação no Parlamento. Como esse umbral era inferior ao quociente eleitoral na maioria dos estados, o princípio nunca teve aplicação prática. Desde aquele ano até hoje, em mais de cinco oportunidades diferentes, sua aplicação vem sendo sucessivamente tentada e invariavelmente procrastinada. Nessa matéria, apenas repetimos a experiência herdada do Império, quando as mudanças no sistema eleitoral tardavam entre os 30 anos a que aludia Nabuco, na biografia do pai, e nos 47 anos que separam a proposta do deputado Ferreira França, de 1835, e a Lei Saraiva, que a instituiu em 1881.

Em recente e polêmica decisão, o Supremo Tribunal Federal inviabilizou a aplicação do dispositivo contido no art. 13 da Lei dos Partidos (Lei no 9.096, de 19/9/1995), inquinando-a de inconstitucional, depois que a Constituinte de 1987-88, ao ignorar o requisito do desempenho eleitoral mínimo, invalidou todas as tentativas anteriores de aplicá-la, desde 1978 (ver Emenda Constitucional $\mathrm{n}^{\mathrm{o}}$ 11). Para evitar a existência de mais de uma dezena de partidos de pequena expressão política e eleitoral, como aconteceu nas legislaturas que se seguiram à redemocratização em 1945, depois do Estado Novo, e à restauração democrática, depois do regime militar, quando 19 legendas tiveram assento na Câmara dos Deputados, a fixação de uma cláusula de desempenho tornou-se fundamental para desobstruir e tornar operativo o processo decisório noLegislativo. Aefetivaçãodessa tentativa que data de mais de 40 anos, por já estar prevista na versão original do Código Eleitoral de 1965 (atual art. 7o, § 1o da Lei dos Partidos, n⿳09.096/95), é requisito para a formação de maiorias estáveis no Congresso Nacional, e em especial na Câmara dos Deputados, cuja representação é escolhida pelo sistema proporcional desde 1932 (verCódigo Eleitoral, de Getúlio Vargas, que teve Assis Brasil, talvez, como seu principal mentor). É indispensável ressalvar, contudo, que a adoção da cláusula de desempenho nas eleições não guarda relação direta com as exigências para a fundação de novos partidos.

O quadro partidário, que será, assim, resultado da modalidade do sistema eleitoral que adotarmos, implicando a aplicação da cláusula de desempenho, segundo a tendência revelada nos três últimos pleitos, na existência de não mais de seis a oito partidos representados na Câmara dos Deputados. Embora muito se tenha discutido sobre a relevância ou não de se tomar em conta o número de partidos de cada sistema político, vale a advertência do professor Giovanni Sartori, em sua obra Partidos e Sistemas Partidários. Diz ele,

"Para começar, o número de partidos indica imediatamente, ainda que de modo apenas aproximado, uma característica importante do sistema político: à medida que o poder político está ou não fragmentado, disperso ou concentrado. Analogamente, só ao saber quantos partidos existem, somos alertados para o possível número de 'correntes de integração’ que intervém em cada sistema. Como assinala Gunnar Sjöblon, dois partidos não permitem mais que uma corrente de integração recíproca; três partidos permitem três correntes de integração, quatro partidos seis correntes, cinco partidos dez correntes, seis partidos quinze, sete partidos 21 correntes".

E este é um fator que obviamente dificulta, quando não impede, a celeridade de qualquer processo decisório, servindo de obstáculo à busca do consenso.

Mantendo-se tanto o sistema proporcional, segundo o modelo vigente, ou o denominado sistema misto, de extração alemã, a cláusula de desempenho tem por objetivo não impedir a fundação nem o funcionamento dos partidos, porém, antes, o de assegurar a governabilidade e até mesmo a operosidade do sistema político. Esse foi o objetivo de sua adoção pela Alemanha. Já a implantação do sistema proporcional em listas, abertas ou não-bloqueadas, ficaria condicionada à sua compatibilidade com o modelo de informatização das eleições que usamos no Brasil.

O grande inconveniente apontado na modalidade de listas fechadas e bloqueadas é a influência decisiva das cúpulas, ou das claques partidárias na escolha dos 
candidatos. Essa restrição, no entanto, pode ser prevenida pela exigência de que as convenções partidárias destinadas a escolher os candidatos, em todos os níveis, atendam à existência da participação numa proporção mínima de filiados, garantia que, além de assegurar a democracia interna no âmbito partidário, teria o dom de acentuar o papel ativo e os direitos dos militantes.

\section{SISTEMAS DE GOVERNO}

Sistemas eleitorais e sistemas de governo não oferecem muitas opções ao princípio do que se convencionou chamar de "engenharia política". Os primeiros são proporcionais ou majoritários, ou são mistos, resultado da combinação das duas alternativas. É o caso alemão, em que o eleitor tem direito a dois votos: no primeiro, elege o candidato que disputa a vaga no distrito, pela modalidade de maioria simples, e no segundo, escolhe a lista partidária de sua preferência votando no partido e não no candidato. Tenha-se em conta, contudo, que a regra de conversão é proporcional, istoé, o número de cadeiras de cada legenda no Bundestag, a Câmara Baixa, é rigorosamente simétrico com a proporção de votos dados nas listas partidárias.

Os sistemas de governo admitem as mesmas três alternativas. São presidencialistas, parlamentaristas ou mistos, designados, indistintamente, de semipresidencialistas ou semiparlamentaristas. O presidencialismo em que se instituiu o cargo de primeiroministro, de livre escolha do presidente da República, sem a ratificação da maioria parlamentar, como simples coordenador da ação administrativa do Executivo, pode ser chamado por essa prática de semiparlamentarista. Da mesma forma, o parlamentarismo de países como França, Portugal, Áustria, Finlândia e Irlanda, em que o presidente da República não é escolhido indiretamente pelo Parlamento, mas pelo voto direto dos eleitores, pode, pela mesma razão, ser chamado de semipresidencialista.

Sistemas eleitoral e partidário, com as configurações acima descritas, são plena- mente compatíveis com o modelo presidencialista que adotamos há 118 anos, da mesma forma como não são incompatíveis com nenhuma destas dos diferentes parlamentarismos hoje vigentes em diversos países. Em ambos os casos, eles permitem o controle da proliferação partidária e têm o objetivo primacial de admitir a formação de maiorias estáveis, garantindo a governabilidade, que outra finalidade não tem senão a de assegurar a capacidade de resposta às demandas da sociedade. A teoria da representação, aprimorada desde Edmond Burke em seu discurso aos eleitores de Bristol, em novembro de 1774, defendeu a autonomia do mandato parlamentar, buscou atender, simultaneamente, a dois objetivos essenciais de todo o sistema de governo: assegurar a governabilidade e garantir a diversidade, representada pelo pluralismo. Como são propósitos que dependem de uma só função, a da representação, torna-se impossível maximizá-las. Se aumentarmos as medidas que ampliam a diversidade, diminuiremos proporcionalmente a governabilidade. $\mathrm{Na}$ proporção em que aumentamos a governabilidade, constrangemos a diversidade. Seu equilíbrio, por conseguinte, é fundamental para a estabilidade e a funcionalidade de todo o sistema de governo.

No regime presidencialista, a existência de maiorias estáveis no Congresso é sempre útil e desejável. Em qualquer das modalidades do parlamentarismo, à exceção do sistema inglês, mais que desejável, ela é essencial porque, sem maioria parlamentar, não há governo.

Disso resulta a vantagem que o presidencialismo pode ter sobre o parlamentarismo. O sistema de freios e contrapesos do presidencialismo norte-americano, por exemplo, é freqüientemente testado pela circunstância de que os mandatos presidenciais têm a duração de quatro anos e os de deputados de apenas dois, renovando-se, portanto, no início e no meio dos períodos presidenciais. Não são poucos os presidentes que, como Bill Clinton, governaram sem ter maioria na Câmara nem no Senado. Esta, por sinal, é a situação do atual presidente George Bush, nos dois últimos anos do seu 
segundo período de governo. A soma de poderes presidenciais nos Estados Unidos da América do Norte, inclusive o de ter seus vetos mantidos, a não ser quando rejeitados por dois terços, permite a existência de governos sem maioria no Congresso. Nestas condições, a variável eleitoral é condicionante do sistema partidário e ambos o são do sistema de governo.

Em 1821, data da primeira eleição levada a efeito em todas as províncias para a escolha dos seus representantes às Cortes Gerais Extraordinárias e Constituintes da Nação Portuguesa até o Código Eleitoral de 1932, o Brasil adotou o sistema majoritário, nas suas várias modalidades, com a Lei do Terço e a Lei dos Círculos, vigentes no Império. O sistema proporcional, por sua vez, vem sendo aplicado há pelo menos 75 anos, com exceção no Estado Novo, período em que não houve eleições. Qualquer de suas modalidades, pois, não deve ocasionar grandes mudanças noperfil da representação política do país no que tange às Câmaras Municipais, Assembléias Legislativas, Câmara Legislativa do Distrito Federal e Câmara dos Deputados. O mesmo não se pode esperar de eventual mudança que implique a adoção do sistema majoritário, na modalidade distrital, hipótese que, para muitos, poderia acarretar a municipalização das questões nacionais, uma vez que, sob essa ótica, provavelmente, seriam tomadas as decisões por representantes de forte vinculação aos interesses locais.

\section{FUTURO DA REFORMA POLIITICA}

Se considerarmos as hipóteses de trabalho sobre as quais o Congresso tomará suas decisões, se o fizer na atual legislatura, como seria desejável, é possível concluir que ela se circunscreverá a alguns poucos temas que mais despertam o interesse da opinião pública.

O primeiro é, seguramente, a transcendente questão da fidelidade partidária, sobre a qual já se pronunciou o Tribunal Superior Eleitoral, apoiando a tese, a meu ver, correta, de que os mandatos dos eleitos pelo sistema proporcional em vigor no país pertencem aos partidos e não aos candidatos. Como se trata de matéria ainda pendente de apreciação pelo Supremo Tribunal Federal, e também do conjunto de propostas já aprovadas pelo Senado e há tempo submetidas à decisão da Câmara, é possível estimar que a solução ou virá por poder judicial, ou será pela via congressual.

O segundo é o problema da cláusula de desempenho por ter sido o art. 13 da Lei dos Partidos Políticos entrevisto como inconstitucional em decisão adotada pelo plenário do STF. Isso importará em buscar novas alternativas para a sua materialização através de Proposta de Emenda à Constituição, já em tramitação no Senado Federal.

$O$ terceiro vincula-se a mudanças no sistema eleitoral, a respeito do qual é possível estabelecer-se consenso, menos pela necessidade de adaptá-lo às contingências institucionais do país do que igualmente por se tratar de requisito para viabilizar o financiamento público das campanhas, considerado uma espécie de panacéia para pôr fim à influência do poder econômico.

O quarto, como assinalamos acima, é exatamente o financiamento público das campanhas, conseqüência e não causa das mudanças que terão de ser feitas no sistema eleitoral para que possa ser viabilizado.

Não podemos deixar de considerar, todavia, que mudanças nas regras que disciplinam o direito de voto só podem operar-se até o mês de setembro, no $1^{\circ} \mathrm{e}$ no $3^{\circ}$ ano de cada legislatura, em face do que dispõe o art. 16 da Constituição: “A lei que alterar o processo eleitoral entrará em vigor na data de sua publicação, não se aplicando à eleição que ocorra até um ano da data de sua vigência".

Resta considerar, por fim, que as alterações projetadas podem contribuir para aprimorar este ou aquele aspecto das chamadas reformas institucionais. Mas, seguramente, estarão ainda longe de solucionar o contencioso que constitui uma ampla, necessária e recomendável reforma, nos termos em que a concebo. 


\section{A IMPORTÂNCIA DAS INSTITUIÇCÕES}

As reformas institucionais, pelas quais me empenho ao longo das três últimas décadas, devem, por conseguinte, ultrapassar o universo das alterações das leis eleitorais e partidárias, aprimorar o sistema de governo, removendo inclusive as áreas de atrito em poderes, promover o fortalecimento da federação, indispensável à efetiva descentralização do exercício do governo num país de grande extensão territorial e de enorme expressão demográfica e o revigoramento dos valores republicanos, tão derruídos, e ensejando, como verberou, há cem anos, Joaquim Murtinho, "a republicanização da República".

Este parece constituir, a meu juízo, o nosso maior desafio - o de vertebrar duradouras instituições.

Úteis, a propósito, considero as observações de Norberto Bobbio, em seu livro Entre duas Repúblicas, em que analisou, ao fim da Segunda Guerra Mundial, a conjuntura em que vivia a Itália e os rumos da Constituição de 1946 que, lá como aqui, buscava devolver a ambas as nações a democracia banida, lá pelo fascismo, aqui pelo Estado Novo. A transcrição de alguns trechos do livro citado, com respeito ao Brasil, é de extraordinária atualidade:
"Há ainda quem diga que a política é questão de homens... Essas pessoas são, hoje, as mesmas que vão aumentar a fila dos desiludidos, porque descobrem que nem todos os governantes são Péricles, e nem todos os membros do governo dos Comitês de Libertação Nacional são Catão".

E, mais adiante, sentencia:

"Por isso, para quem insiste em dizer que é [a política] é questão de homens, respondemos com absoluta segurança que é questão de instituições. Os homens, em sua maioria, são aquilo que são: as boas instituições revelam as qualidades positivas, as más instituições, as negativas... Ora, recriminar a malvadeza dos governantes, quando as instituições não são boas, é, no mínimo, tão absurdo quanto esperar que os governantes se tornem providencialmente sábios sem que as más instituições sejam removidas... A nossa cura somente virá com boas instituições".

As reformas, frise-se, são impostergáveis para que de uma democracia procedimental passemos para uma democracia decisional, capaz de assegurar regras claras indispensáveis ao jogo político compatível com a estabilidade institucional e a segurança jurídica que a nação reclama. 